\title{
Notas Sobre Suicídio no Trabalho à Luz da Teoria Crítica da Sociedade
}

Notes On Suicide At Work Based On The Critical Theory Of Society

Notas Sobre Suicidio En El Trabajo En Vista De La Teoría Crítica De La Sociedad
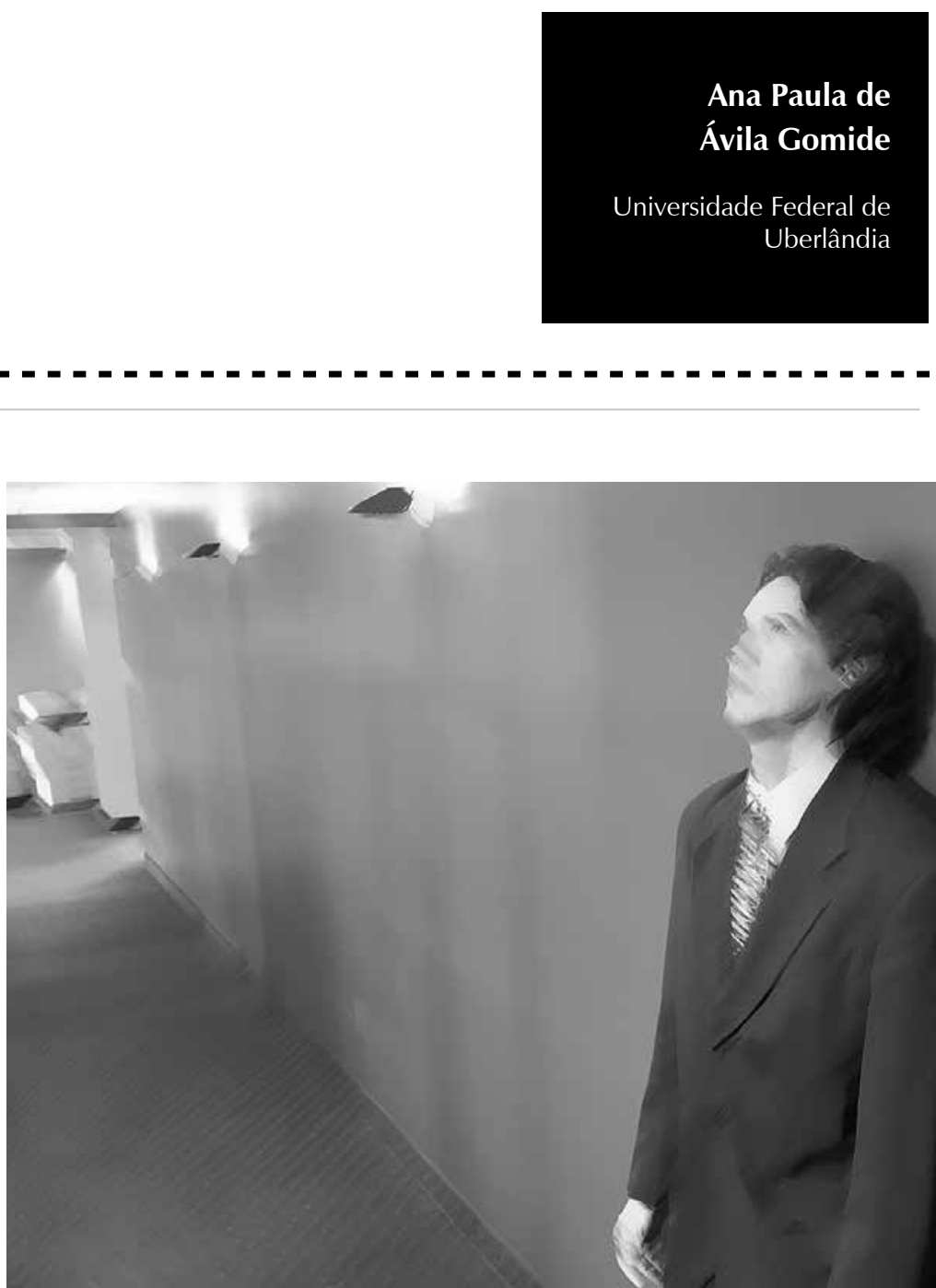
Submissão à morte é submissão ao senhor da morte: a pólis, o estado, a natureza, ou deus. O juiz não é o indivíduo, mas um poder mais alto; o poder sobre a morte é também o poder sobre a vida. Mas isso é só metade da história. A outra metade é a disposição, o desejo de desistir de uma vida de mentiras uma vida que trai não somente os sonhos de infância mas também as esperanças e promessas amadurecidas do homem.

(Herbert Marcuse em A Ideologia da Morte, 1959).

Resumo: Tendo como ponto de partida as discussões de Cristophe Dejours sobre o suicídio ligado às novas organizações de trabalho no mundo contemporâneo, este trabalho visa a apontar mais elementos teóricos para a discussão do problema a partir do referencial da teoria crítica da sociedade. Os escritos de Adorno, Horkheimer e Marcuse oferecem um arsenal conceitual profícuo para o tema em questão, no sentido de iluminar a atual forma histórica pela qual o progresso e o cientificismo técnico - a racionalidade instrumental - têm se objetivado. As formas de organização do trabalho nas empresas sob a gestão do terror mobilizam e fortalecem nos indivíduos seus traços autoritários, características individuais tornadas necessárias à produção e adequadas ao clima social com tendências destrutivas. Enfim, o sofrimento no trabalho é entendido como reflexo da deformação da subjetividade pela forma social imperante de trabalho alienado das sociedades pós-industriais, assim resultando no chamado trabalho morto - o ato suicidário de um trabalhador no seu local de trabalho.

Palavras-chave: Teoria crítica. Stress ocupacional. Condições de trabalho. Suicídio.

Abstract: Taking as a starting point the discussions about suicide from Cristophe Dejours on the new work organizations in the contemporary world, this work aims at pointing the theoretical elements for the discussion of the problem, on the grounds of the critical theory of society. The writings of Adorno, Horkheimer, and Marcuse offer a useful conceptual tool about the topic in order to enlighten how the current historical form in which the instrumental rationality has been objectified. Forms of work organization in enterprises under the "terror management" mobilize and empower individuals in their "authoritarian traits", individual characteristics which are required for production and appropriate for the destructive tendencies in the current social context. Finally, suffering at work is understood as a reflection of the deformation of subjectivity by the prevailing social form of alienated work in post-industrial societies, thus resulting in the so called "dead work" - the suicidal act of an employee in his/her workplace.

Keywords: Critical theory. Occupational stress. Working conditions. Suicide.

Resumen: Teniendo como punto de partida las discusiones de Cristophe Dejours sobre el suicidio relacionado a las nuevas organizaciones de trabajo en el mundo contemporáneo, este trabajo visa apuntar más elementos teóricos para la discusión del problema desde el referencial de la teoría crítica de la sociedad. Los escritos de Adorno, Horkheimer y Marcuse ofrecen un arsenal conceptual proficuo para el tema en cuestión, en el sentido de alumbrar la actual forma histórica por la cual el progreso y el cientificismo técnico - la racionalidad instrumental - se han objetivado. Las formas de organización del trabajo en las empresas bajo la gestión del terror movilizan y fortalecen en los individuos sus trazos autoritarios, características individuales que se volvieron necesarias a la producción y adecuadas al clima social con inclinaciones destructivas. En fin, el sufrimiento en el trabajo es entendido como reflejo de la deformación de la subjetividad por la forma social imperante de trabajo alienado de las sociedades post industriales, así resultando en el llamado trabajo muerto - el acto suicida de un trabajador en su lugar de trabajo.

Palabras clave: Teoría crítica. Estrés ocupacional. Rendimento laboral. Suicidio.

Tendo como ponto de partida os estudos de Cristophe Dejours sobre o suicídio ligado às novas organizações de trabalho no mundo contemporâneo (Dejours, 2007; Dejours \& Buègue, 2010), nosso objetivo é levantar mais elementos teóricos e conceituais para um tema tão complexo quanto o do suicídio no trabalho. Para tal, buscamos nas discussões lançadas pelos filósofos frankfurtianos sobretudo, Adorno, Horkheimer e Marcuse - dirigidas às sociedades pós-industriais e aos seus mecanismos de dominação sobre a subjetividade uma abordagem que prima pela interdisciplinaridade, na tentativa de elucidar o clima totalitário que se estabelece no mundo laboral. Cumpre ressaltar que não se trata de tentar estabelecer afinidades ou contrapontos entre o pensamento de Dejours e o dos autores da teoria crítica, visto que, é claro, o primeiro é um autor reconhecidamente estudioso do tema e um dos maiores expoentes sobre o assunto na atualidade, o que não se pode dizer dos frankfurtianos. Não obstante, a teoria crítica da sociedade oferece um arsenal teórico e conceitual profícuo para o tema em questão, no sentido de iluminar a atual forma histórica pela qual o progresso e o cientificismo técnico - a racionalidade instrumental - têm se objetivado, tendo em vista as 
concomitantes transformações de formas de organização do trabalho nas empresas e seus efeitos psicossociais sobre os indivíduos, em termos de neles fortalecer e de mobilizar seus traços autoritários.

As críticas assertivas e mais abrangentes de Adorno e Horkheimer a respeito da dialética do esclarecimento, de que os rumos tomados pela razão ocidental exigiram a reprodução do horror como condição de desenvolvimento das forças produtivas assim culminando no recrudescimento da barbárie (Horkheimer \& Adorno, 1944/1985) -, enriquecem as reflexões e as análises sobre o sofrimento no trabalho. Nesse sentido, o sofrimento é entendido como reflexo da deformação da subjetividade pela forma social imperante de trabalho alienado, tal como discutido, também, por Marcuse (1955/2009, 1957/1970).

A análise a ser aqui empreendida parte do campo da psicodinâmica do trabalho, mas avaliando essa problemática dentro de uma tendência social e histórica mais ampla, cujas implicações na psicologia das pessoas (na subjetividade) devem ser consideradas, ou seja, tentamos atribuir ao suicídio no ambiente laboral não a leitura de que esse seja um ato desesperado de recusa do indivíduo que não mais quer se deixar dominar $^{1}$ - e cuja identidade (profissional e particular) foi destroçada pelas pressões do trabalho -, mas sim, o reflexo de um consentimento silencioso, por parte do sujeito, com as tendências destrutivas e totalitárias instaladas no mundo do trabalho: a concordância de sacrificar a si mesmo. Sob essa ótica, também perguntamos: a vida, hoje, tem de fato se reduzido à adaptação, e se a melhor perspectiva de vida é a adaptação às condições desumanas, como os sujeitos reagem psicologicamente a essas contradições? Ora, a percepção dos sujeitos de que o trabalho e seus produtos não trazem a perspectiva de uma sociedade justa e racional não tem sido suficiente para romper essa situação de alienação; ao contrário, tem ampliado tal condição e, ainda mais, impulsionado os sujeitos ao abandono de vínculos sociais (no caso, tornando-se a empresa o único referencial de vida), o que tem ocasionado a morte psíquica e, fatalmente, o suicídio.

\section{Uma digressão necessária: trabalho e suicídio depois de Auschwitz}

O suicídio de Walter Benjamin, em setembro de 1940, na fronteira franco-espanhola, mais do que um último gesto de desespero para não cair nas mãos da Gestapo, pode ser visto como uma forma de denúncia dos entraves para uma possível felicidade sob as condições de vida desumanas regidas pelas leis do capital no século XX. Frente ao horror do totalitarismo, cujas formas políticas na Europa ocidental (nazismo na Alemanha e fascismo na Itália) atendiam aos interesses dos grandes trustes do capitalismo tardio, o intelectual judeu que amava os livros e a arte - e que, recalcitrante aos costumes burgueses e aos rumos tomados pelo progresso, elaborara críticas contundentes ao capitalismo -, não teve como sobreviver ao fascismo sem se renegar. Sua morte é o testemunho da dificuldade de um pensador, sobretudo judeu, para continuar vivo sob o fascismo: "Os sete últimos anos da vida de Benjamin constituem uma fuga sem trégua da perseguição política e também uma luta perpétua pela sobrevivência material" (Gagnebin, 1982, p.9). Também frente à pressão do totalitarismo, o escritor austríaco Stefan Zweig deu fim à própria vida depois de muitos anos de exílio forçado por causa 
da perseguição dos nazistas. Não por acaso, o suicídio desses intelectuais é aqui citado, ressaltando-se a situação asfixiante e sem saída para Benjamin e Zweig, submetidos a condições sociais objetivas permeadas de horror e de tortura que ocasionaram o morticínio e a destruição racionalmente generalizada e administrada pelos altos e médios escalóes do partido nazista contra milhares de pessoas inocentes. Trata-se de pessoas que foram perseguidas pelo regime totalitário, por meio de seus mecanismos políticos e sociais apelativos contra a razão e a vida intelectual e cultural, que, não obstante, mobilizaram nas massas o desejo irracional de aderir à organização nazifascista delirante.

$\mathrm{O}$ ato suicida de um indivíduo como resultante de uma situação de opressão e de não liberdade, geradora de sofrimento físico e de redução do humano a um simples objeto descartável, ou a mera engrenagem do sistema, é mais comum hoje em dia do que podemos prever, mesmo (e principalmente!) em tempos de democracia neoliberal do século XXI. Atentamos para o suicídio no local de trabalho que, no mundo contemporâneo, tem mostrado a que ponto a degradação e a precariedade das relações de trabalho chegaram, juntamente ao enfraquecimento das ações políticas e solidárias coletivas necessárias para o enfrentamento, pelos homens, das condições desumanas que vão contra seus interesses racionais, essas, presentificadas ao máximo nas empresas. Tais atos extremos são consequência da funesta mentalidade administrativa aplicada nas organizações empresariais que, dentro de uma crítica mais abrangente, apresenta similaridades com os princípios nazifascistas de administração burocrática, quais sejam: a organização científica voltada para a intensificação da força de trabalho dos sujeitos, que traz em seu bojo elementos irracionais ao colocar questões econômicas, quantitativas e produtivas acima do bem-estar e da felicidade humanas, à custa da exclusão e da morte daqueles considerados fracos, não adaptados, entre outros fatores (Dejours, 2007). A respeito das aberrações do Holocausto, pensadores que se dedicaram a pensar sobre as crises do mundo contemporâneo (Adorno, 1969/1995; Arendt, 1963; Bauman, 2001) têm justamente demonstrado como os princípios da organização moderna burocrática, para a efetivação do maquinário nazista, foram conduzidos por pessoas aparentemente comuns que acabaram por introjetar os princípios calculistas e de eficiência, cujos fins eram o de fazer que a máxima racionalização criasse uma distância entre os perpetradores do morticínio e as vítimas dos campos de concentração.

Para Dejours (2007), inspirado nas obras de Hannah Arendt, a banalização do mal, atualmente encontrada nas demais formas de injustiça social (o desemprego crescente, o aumento da violência social e a xenofobia na Europa), torna-se patente com a disseminação, a partir da década de 80 , do modelo econômico calcado no neoliberalismo. Tal modelo integrou sua lógica beligerante à sociedade como um todo no sentido de instilar nas pessoas a crença de uma guerra econômica mundial, na qual os imperativos do combate, da competição e do remanejamento de grupos sociais pela ciência (assim intensificando e endossando as políticas mundiais de segregação étnica, religiosa e racial) se tornaram normas. Dessa forma, as crueldades praticadas no mundo do trabalho para excluir os menos aptos ao combate transformaram-se em elementos indispensáveis, senão naturais, dentro da lógica empresarial, ao lado da política de banalização do sofrimento de outros que 
acabou por corroborar a mentalidade de que as vítimas do desemprego e da pobreza - e também os trabalhadores despreparados para a guerra - são responsáveis pelos seus tristes destinos. Não à toa, sobre tais princípios apontados, levantamos a ideia de que esses se encontram na base das técnicas gerenciais difundidas na empresa moderna e nas escolas de Administração que determinam as novas organizações no mundo do trabalho (Santos, 2009). A partir dessas reflexões, até que ponto se pode afirmar que sob as novas organizações de trabalho se encontra a continuidade histórica de condições sociais objetivas e subjetivas que permitiram a antecâmara de Auschwitz? (a saber, a racionalização da linha de produção industrial do terror e da morte?). A questão acima colocada tem também como pano de fundo as discussões levantadas por Dejours (2007, 2010) a propósito das defesas psíquicas de trabalhadores contra a deterioração do trabalho, resultantes das técnicas corriqueiras

2 Das interpretações estabelecidas sobre as relações entre o suicídio e o trabalho, uma que serve para encobrir a responsabilidade da organização empresarial e enfraquecer propostas de ações políticas no mundo do trabalho é a que tenta atribuir as causas do suicídio do indivíduo aos seus problemas de personalidade, como se o sujeito fosse o único responsável pelo ato, incapaz de lidar com as pressões do seu ambiente de trabalho, consideradas pela lógica empresarial como naturais e imprescindíveis à produção. de assédios ou de pressões por parte da direção empresarial sobre o trabalhador, em nome da racionalidade técnica, disseminadas nas novas organizações do trabalho.

E, frente a esse quadro sombrio de práticas corriqueiras de crueldade e de resignação por parte dos trabalhadores já adoecidos e fragilizados por tais técnicas gerenciais - posto que transformados em objetos para o funcionamento da empresa -, o ato suicidário de um trabalhador no seu local de trabalho revela uma mensagem brutal, além de expressar a máxima encontrada nas sociedades ultraindividualistas, qual seja: a de que a vida matável, perpetrada pela lógica do sacrifício individual e encontrada nos inúmeros exemplos de vidas descartáveis, é fator integrante para o funcionamento da economia mundial - ou o sujeito se adapta às condições de desumanização ou morre.
Dessa mensagem endereçada aos que ficam e aos que continuam participando de tais relações perversas, Dejours ainda aponta uma série de manifestações psicopatológicas que tornam as pessoas insensíveis contra aquilo que as faz sofrer, assim tornando a situação de desumanização aceitável, e o medo e a angústia, condizentes com o sofrimento gerado no ambiente de trabalho, escamoteados e renegados a ponto de a morte de um colega configurar-se perante os demais como um ato banal². E, é claro, conforme foi assinalado, o cenário no qual se desenvolvem tais condições desumanas é o do modelo econômico atual, tendo em vista seu modelo de racionalidade instrumental perpetrado pelas leis do mercado e internalizado por grande parte de pessoas os tipos sociais mais afinados com a tendência histórica de uma sociedade burguesa subordinada à racionalização progressiva da produção industrial e à lógica do princípio de equivalência (Adorno, 1959/2010).

Para os intuitos deste ensaio, ressaltamos que, diferentemente das minorias perseguidas pela Gestapo (os judeus e todos os considerados párias da sociedade), os sujeitos que atentam contra as próprias vidas no local de trabalho são justamente as pessoas consideradas adaptadas ao sistema por possuírem um emprego (inclusive, até altos cargos nas multinacionais e nas grandes empresas), e que se esforçam - ou se esforçaram para se ajustar aos desígnios da produção ao preço da própria mutilação psíquica. Vivemos ainda em tempos sombrios sob formas talvez mais perversas e transparentes em termos do sacrifício individual exigido para a sobrevivência e o funcionamento do sistema, cuja irracionalidade objetiva, em nome de uma falsa racionalidade econômica, tem se sobreposto aos valores humanos. No tocante ao fundamento das relações 


\footnotetext{
Dejours e Bègue (2010) afirmam que um tipo de sofrimento no trabalho que conduza ao isolamento e à depressão do sujeito a ponto de ele cometer suicídio no local de trabalho se deve às condições de injustiça e de assédio que hoje em dia se tornaram cada vez mais comuns nas empresas.
}

econômicas internacionais e ao mundo do trabalho, caminhamos para um novo holocausto cientificamente planejado em nome do lucro e da produtividade de grandes empresas que, agora, sob o discurso da guerra econômica, adotam formas de organização de trabalho voltadas para a exploração e a intensificação máxima da força de trabalho, fomentando a competitividade entre os indivíduos (Dejours, 2007). Os setores mais poderosos da indústria no capitalismo tardio - aço, petróleo, automobilismo, eletricidade, química, telecomunicações - têm introduzido novos métodos de avaliação do trabalhador, em particular, a avaliação individual do desempenho e a introdução de técnicas ligadas à chamada qualidade total, cujas repercussões na vida dos sujeitos têm sido as piores possíveis: trata-se de instrumentos de controle cruéis e desumanos que têm fortalecido um tipo de darwinismo social no ambiente de trabalho. E aquele que não se conforma ou não consegue adaptar-se ao clima de ameaça social oriundo das pressões enfrentadas no trabalho, assim correndo o risco de impotência econômica e de exclusão, acaba por pagar o preço com a própria vida ou, no mínimo, por introjetar condutas exigidas que perpetuam a própria alienação e servidão psíquica.

Não é demais lembrar a frase de Adorno (1969/1995) "que Auschwitz não se repita!", cuja preocupação era a de alertar sobre a possibilidade de que tal sistema bárbaro encontrado nos campos de concentração pudesse tornar-se regra no mundo contemporâneo, passível de desdobrar-se em novos fenômenos. Ora, nada mais atual e contundente que a afirmativa de Adorno! No mundo do trabalho, tendo em vista o grau profundo de degradação do "conjunto do tecido humano e social do trabalho" (Dejours \& Buègue, 2010) - a despeito dos entusiastas tecnológicos e defensores do neoliberalismo que afirmam serem as condições dos empregados, nas empresas, as melhores possíveis com os novos métodos de gestão e com a robotização -, a ameaça de Auschwitz, para além de uma alegoria, continua mais presente do que nunca.

\section{A gestão do terror: a administração do trabalho morto}

$\mathrm{Na}$ linha de estudos que relacionam o trabalho com os processos de saúde-doençasofrimento do trabalhador, destacamos os da psicodinâmica do trabalho. Dentro dessa linha, o trabalhador não é visto como um receptor passivo de agentes provocadores de doença, mas, ao contrário, participa desse processo ao desenvolver sistemas defensivos contra o sofrimento psíquico e físico advindos dos modelos de organização do trabalho no qual está implicado (Heloani, 2011). Dejours, dentro dessa linha de estudo, destaca que, quando no trabalho se intensifica a sua dimensão patogênica a saber, modelos de gestão que minam a autonomia do trabalhador e que impedem o seu reconhecimento no trabalho, assim intensificando aspectos identitários conflitivos -, os sujeitos podem lançar mão, em último caso, do suicídio.

Dejours e Bègue (2010) afirmam que um tipo de sofrimento no trabalho que conduza ao isolamento e à depressão do sujeito a ponto de ele cometer suicídio no local de trabalho se deve às condições de injustiça e de assédio que hoje em dia se tornaram cada vez mais comuns nas empresas. A introdução de novos métodos de gestão na organização do trabalho tem como finalidade introduzir técnicas de avaliação individual de desempenho, juntamente às medidas de 
qualidade total, para averiguar a qualidade de serviço oferecido pelas empresas, a partir do qual os assalariados são impelidos a burlar a ética profissional (e a si mesmos) para atingir os padrões da suposta qualidade colocada pelos gestores. Nas palavras de Dejours e Bègue:

No momento em que a colonização do mundo pelos novos métodos de gestão estava em seu ápice, um novo método de organização, estreitamente ligado à doutrina gestionária, é introduzido na maioria das empresas privadas e mesmo no serviço público. Trata-se da avaliação individualizada do desempenho. Esse método é apresentado como meio 'objetivo' de avaliar o trabalho de cada indivíduo, de torná-lo comparável ao trabalho dos outros assalariados. A avaliação individualizada assenta-se no princípio de uma análise quantitativa e objetiva do trabalho, passando pela mensuração dos resultados (2010, p.44)

Entretanto, os autores lembram que a avaliação do trabalho por métodos objetivos e quantitativos de mensuração se assenta em bases científicas falsas, posto ser impossível mensurar o trabalho propriamente dito - a mensuração do tempo psíquico e intelectual que um trabalhador emprega no seu trabalho para a realização das competências necessárias para se atingir os objetivos propostos pela empresa. Tais fundamentos científicos têm como princípios o cálculo utilitário e a lógica da razão instrumental, que se tornaram valores sociais preponderantes da sociedade capitalista. O suporte de dominação psíquica agenciado pelas técnicas de avaliação individual do trabalhador tem efeitos deletérios sobre a saúde mental, pois acaba por gerar sentimentos de injustiça nos sujeitos avaliados (o lucro e o faturamento de uma empresa não estão diretamente relacionados ao desempenho do trabalhador), assim como criar um clima de competitividade entre os colegas, minando os sentimentos de cooperação no seio das empresas e de pertencimento a uma coletividade. Essas avaliações trazem em seu bojo as ameaças de exclusão e de demissão, assim como a desestabilização da identidade dos assalariados. Assim, dizem os autores que

A avaliação individualizada dos desempenhos introduz concorrência entre serviços, entre departamentos, entre sucursais, mas também entre os próprios assalariados (...). Mas se acrescentarmos à avaliação individualizada do desempenho a ameaça de ser colocado na 'geladeira', da transferência sumária, da queda em desgraça, da demissão, então o método gera não apenas o cada-um-por-si, mas ainda faz surgir rapidamente, para além da 'emulação saudável', condutas de concorrência e de rivalidade que derivam em condutas desleais: retenção de informações, boatarias, 'rasteiras', etc. A lealdade e a confiança são corroídas e são trocadas pela desconfiança e pelo constrangimento dos colegas, logo considerados como adversários (Dejours \& Bègue, 2010, p.46)

Esses métodos são empregados a fim de excluir os que não estão aptos para os objetivos da produtividade, e de exigir daqueles considerados fortes, produtivos e combativos, desempenhos sempre superiores em termos de disponibilidade, de disciplina, de abnegação e de subserviência aos valores da empresa. Segundo Dejours, "o privilégio concedido à gestão, em detrimento do trabalho" (2010, p.27) tem desestruturado os coletivos e desestabilizado psicologicamente os sujeitos em prol da busca de objetivos almejados pelas empresas sob as políticas de reestruturação produtiva. Isso também se relaciona às crises enfrentadas pelas organizações políticas e sindicais com a emergência das culturas empresariais forjadas por países como Estados Unidos e Japão, em que a identidade e a realização dos sujeitos se encontra na sua adaptação às empresas, acenando a ideia de que o principal meio de 
referência para o trabalhador é o seu trabalho e a função que nelas exerce (Dejours, 2007).

A indiferença pelo sofrimento psíquico dos que trabalham também tem suas raízes no "descompasso histórico das organizações sindicais com a questão da subjetividade e do sofrimento" dos trabalhadores, o que contribuiu para um clima de intolerância ao sofrimento gerado pelos novos métodos de gestão que, não por acaso, têm minado reações coletivas contra as adversidades sociais e psicológicas causadas também - e principalmente-pelo desemprego (Dejours, 2007). A respeito do sofrimento subjetivo historicamente negado pelos sindicatos e pelos movimentos de esquerda, Dejours destaca que: "Afora a saúde do corpo, as preocupações relativas à saúde mental, ao sofrimento psíquico no trabalho, ao medo da alienação, à crise do sentido do trabalho não só deixaram de ser analisadas e compreendidas (pelos movimentos esquerdistas) como também foram freqüentemente rejeitadas e desqualificadas (...)" (Dejours, 2007, p. 38).

As imposições de organização do trabalho geram angústia e uma série de manifestações psicopatológicas nos assalariados, em consonância com a organização econômica que continua obrigando a maioria das pessoas (empregadas ou desempregadas) a defender situações em relação às quais se tornaram impotentes, bem como a se manter em uma situação de alienação e de sofrimento para garantir a sobrevivência material. Confirma-se, assim, o que Adorno e Horkheimer (1944/1985) explanaram acerca da racionalidade dominante: a apologia da autoconservação ou da razão autoconservadora, hoje visivelmente perpetrada pelos setores econômicos e empresariais dominantes na fase monopolista do capitalismo (também citamos os setores educacionais e demais instituições sociais que incorporaram tal lógica de domínio), tem eliminado os sujeitos, sinalizando a questão psicodinâmica de como eles podem resistir a uma racionalidade que é em si mesma irracional, pois ajustada aos mecanismos do mercado e distante das questões humanas. As regressões psíquicas necessárias à adaptação ao todo são mediadas pela estrutura econômica e social, sendo a adaptação ao poder não mais resultante da dolorosa consciência moral dos sujeitos ou de um processo dialético entre o sujeito e a realidade, mas sim, produzidas pela engrenagem da indústria. Nas palavras dos autores:

A orientação economicamente determinada da sociedade em seu todo (que sempre prevaleceu na constituição física e espiritual dos homens) provoca a atrofia dos órgãos do indivíduo que atuavam (outrora, na fase liberal do capitalismo) no sentido de uma organização autônoma de sua existência. Desde que o pensamento se tornou um simples setor da divisão do trabalho, os planos dos chefes e especialistas competentes tornaram supérfluos os indivíduos que planejam sua própria felicidade. A irracionalidade da adaptação dócil e aplicada à realidade torna-se, para o indivíduo, mais racional do que a razão (...). O progresso da sociedade industrial, que devia ter eliminado como que por encanto a lei da pauperização que ela própria produzira, acaba por destruir a idéia pela qual o todo se justificava: o homem enquanto pessoa, enquanto portador da razão. A dialética do esclarecimento transforma-se objetivamente na loucura (Horkheimer \& Adorno, 1944/1985, p.190)

As formas de organização do trabalho cientificamente articuladas pelo saber administrativo e justificadas pelo discurso economicista (Dejours, 2007) trazem em seu bojo uma lógica irracional, pois contra os interesses dos indivíduos, assim indicando uma extrema desproporção entre a coletividade e os sujeitos, a despeito da 
ideologia corrente que tenta impor a ideia de que a felicidade pode ser encontrada na devoção do empregado à sua empresa. A isso, acrescenta-se a cultura organizacional que tende a colocar as empresas como principais referências identitárias para os sujeitos, em detrimento da cultura e das demais instituições sociais formadoras que poderiam propiciar a eles uma razoável autonomia e reflexão crítica sobre a realidade. Adorno (1956/2010), no texto Teoria da Semiformação, observa que a hegemonia da ideia de formação só voltada para a adaptação ao existente, com seus conteúdos ajustados pelos mecanismos do mercado que se desfaz da ideia de formação espiritual, perpetua a deformidade subjetiva que se pensava dominada nas sociedades modernas tecnológicas, a saber, a tendência à agressão destrutiva e mórbida dos indivíduos e à competição entre eles (Adorno, 1956/2010, p.12). Em consequência disso, a raiva também se volta contra a própria promessa da cultura, que os sujeitos tendem a depreciar ou a não reconhecer (Adorno, 1969/1995). No fundamento econômico das relações sociais, a socialização da semicultura caracteriza hoje a camada de empregados médios, visto que os últimos, privados dos pressupostos necessários para a sua formação (aquela propiciadora tanto da adaptação quanto da autonomia do indivíduo na realidade social) e, sobretudo, do ócio, acabaram por se tornar mais vulneráveis e integrados às malhas do poder, já que o que tem vigorado na sociedade burguesa é a sobrevivência material e a produção econômica, bem como o saber técnico e funcional. Dentro desse quadro de conformismo onipresente, o potencial destrutivo da pseudoformação é lembrado por Adorno, tendo em vista que os homens, subtraídos da promessa da cultura a realização da possível liberdade e felicidade individual para o bem-estar da humanidade, assim como da reflexão crítica sobre a cultura e a civilização -, investem suas frustrações contra o próprio conceito de cultura e de formação espiritual. A respeito da formação cultural revertida em pseudoformação no capitalismo industrial e pós-industrial, Adorno escreve que:

Sua realização (a da formação) haveria de corresponder a uma sociedade burguesa de seres livres e iguais. Esta, porém, ao mesmo tempo, desentendeu-se dos fins e de sua função real, como, de certo modo, ocorre radicalmente, por exemplo, com a estética kantiana, que defende uma finalidade sem fim. A formação devia ser aquela que dissesse respeito - de uma maneira pura como seu próprio espírito - ao indivíduo livre e radicado em sua própria consciência, ainda que não tivesse deixado de atuar na sociedade e sublimasse seus impulsos. A formação era tida como condição implícita a uma sociedade autônoma (...). Contraditoriamente, no entanto, sua relação com uma práxis ulterior apresentou-se como degradação a algo heterônomo, como percepção de vantagens de uma irresolvida bellum omnium contra omnes (1956/2010, p.13)

Trata-se, então, de uma formação social regressiva, não mais atrelada à emancipação do sujeito, mas ao princípio de equivalência e em função do trabalho abstrato e alienado, que tem como mola propulsora os referenciais de uma razão reduzida em força produtiva, o que conduz nossa época histórica a um caminho contrário à emancipação: à barbárie. No plano da subjetividade, confirma-se, assim, o que Freud (1930/1974) postulou acerca do mal-estar na cultura, ou seja, a intensificação da rebelião violenta e irracional contra a civilização que se pauta somente no sacrifício e na renúncia individual, bem como no acirramento de mentalidades preconceituosas encontradas nos diversos grupos sociais passíveis de se sentirem seduzidos pelos crimes e por demais tipos de ações excludentes contra as alteridades. A propósito desse último elemento relacionado 
aos sentimentos narcísicos gerados na civilização (o que Freud denominou "narcisismo das pequenas diferenças"), aludimos às discussões de Dejours a respeito das origens subjetivas do consentimento das pessoas com relação ao seu sofrimento e ao dos outros, por sua vez, também reforçadoras das ideias reproduzidas pela máquina neoliberal de que os homens socialmente discriminados merecem a sua situação de exclusão - seja por causa da incompetência, seja por causa de características pessoais. Dejours afirma que o sofrimento no trabalho, e a participação consentida de trabalhadores que exercem cargos de responsabilidade nas empresas em condições geradoras de desigualdade e de injustiça, a fim de garantir a sobrevivência e o prestígio social, são fatores determinantes para o funcionamento do sistema que, por sua vez, gera um sofrimento crescente entre os que trabalham (Dejours, 2007, p.17). Citamos os gerentes e os responsáveis por departamentos nas empresas que, ao incorporarem o discurso técnico da ciência econômica adotada pelas políticas administrativas empresariais, ostentam um tipo de cinismo ao aplicarem e defenderem as chamadas técnicas de seleção para a elaboração das listas de demissões que visam a livrar as empresas dos chamados parasitas e improdutivos. E os subordinados cada vez mais se sentem ameaçados e expostos ao grande engodo do discurso economicista e tecnicista que subjaz às técnicas seletivas. Entretanto, os que consentem em fazer o trabalho sujo (ou seja, em colaborar com as políticas e técnicas de enxugamento de pessoal em defesa da Realpolitik), contraditoriamente, para continuar no emprego, desenvolvem defesas psíquicas que Dejours (2007) denomina "racionalização do mal" - o cinismo, a depreciação de condutas éticas e morais com a exaltação da virilidade, entre outros -, que acabam por alimentar as condições irracionais da organização de trabalho e, assim, por fechar o grande círculo da injustiça social: a negação do sofrimento alheio, de massas de excluídos, percebidos agora não mais como dignos de preocupação política; ao contrário, os excluídos são depreciados e até mesmo responsabilizados por suas tristes situações sociais. Nas palavras de Dejours:

\begin{abstract}
Esse sofrimento (no trabalho) aumenta com o absurdo de um esforço no trabalho que em troca não permitirá satisfazer as expectativas criadas no plano material, afetivo, social e político. As conseqüências desse sofrimento para o funcionamento psíquico e mesmo para a saúde são preocupantes (...). Mas o sofrimento não desativa a maquinaria de guerra econômica. Ao contrário, alimenta-a, por uma sinistra inversão que cumpre elucidar (...).

Em outras palavras, há uma clivagem entre sofrimento e injustiça. Para os que nela incorrem, o sofrimento é uma adversidade, é claro, mas essa adversidade não reclama necessariamente reação política (...). Evidentemente, quando não se percebe o sofrimento alheio, não se levanta a questão da mobilização numa ação política, tampouco a questão de justiça e injustiça (2007, pp. 18, 19)
\end{abstract}

Assim, podemos pensar o quanto a neutralização da injustiça social por meio da ideologia do realismo econômico e a ocultação do sofrimento psíquico gerado pelas condições irracionais de trabalho tendem a fortalecer as mentalidades propensas aos demais tipos de preconceitos contra os excluídos e os que correm o risco de exclusão, o que contribui, segundo Dejours (2007, p. 91), para o estabelecimento de uma cultura de desprezo nas empresas para os que são excluídos do trabalho por reformas estruturais, ou para os que não conseguem realizar os esforços necessários em termos de carga de trabalho acima do que é estipulado. A psicodinâmica do trabalho, por sua vez, lança luz aos mecanismos 
sociais e psicológicos criados e gerados no ambiente de trabalho que servem para perpetuar uma sociedade desigual e minar as possíveis resistências coletivas ou individuais contra a desumanização. As características psicológicas da banalização do mal e da racionalização da violência e da injustiça, em nome do aparato produtivo providenciado pelas grandes corporações empresariais, são induzidas e mobilizadas pelo trabalho, o que significa ser o mundo do trabalho, tal como hoje se configura pela ideologia neoliberal, um "verdadeiro laboratório de experimentação e aprendizado da injustiça e da iniqüidade" (Dejours, 2007, p.140), ou, como diria Adorno (1956/2010), o modelo social pelo qual hoje se constitui a experiência formativa dos sujeitos reduzida à pseudoformação - a tragédia da formação na sociedade capitalista tardia.

Dejours e Bègue salientam que as políticas empresariais de enxugamento de quadros e de contratação de temporários, e mais o recurso à terceirização, intensificaram o trabalho dos assalariados sob condições de exploração cada vez mais cruéis e degradantes, estabelecendo um quadro de darwinismo social correspondente a um clima de redução dos homens ao "estado de seres naturais", tal como sinalizado por Adorno (1969/1995) a respeito da competitividade exaltada na nossa cultura. A desestabilização psíquica do trabalhador provocada pelas pressões e pela intensificação do trabalho é articulada e calculada, de forma perversa, por especialistas da área - psicólogos organizacionais, gerentes e gestores -, cuja formação técnica é voltada para a aprendizagem do assédio e da disseminação do medo como instrumento de produtividade, em nome da racionalidade técnica (Dejours, 2007). Nesse sentido, Dejours cita as técnicas voltadas para o assédio de trabalhadores a fim de potencializar suas produções, tais como as famosas ameaças de demissão, a pressão para participar da construção da mentira organizacional, as demais humilhações morais, a imposição de condutas no ambiente de trabalho que vão contra as regras da profissão e contra as leis trabalhistas, e mais a pressão social para sonegar informações aos colegas, entre outras. No mundo do trabalho, sob a gestão do terror, podemos afirmar que os traços autoritários são mobilizados nas pessoas em benefício da produtividade, quando homens se tornam coisas e incapazes de experiência ou de identificação com outrem, esse também considerado um objeto. Sob a égide da lógica instrumental encontrada no discurso da ciência administrativa, homens e coisas convergem para o mesmo status quo. Na pesquisa A Personalidade Autoritária (Adorno, Frenkel-Brunswick, Levinson \& Sanford, 1955), a respeito do potencial fascista, Adorno apresenta as características do caráter manipulador, também denominado o tipo de "consciência coisificada", que se distingue pela "fúria organizativa, pela incapacidade total de levar a cabo experiências humanas diretas, por um certo tipo de ausência de emoções, por um realismo exagerado" (Adorno, 1969/1995, p.129). Sobre o caráter manipulador que faz o culto da eficiência e da técnica, Adorno alerta que esse se encontra mais disseminado do que podemos imaginar, para além dos administradores dos campos de concentração e da produção do sistema nazista, levando em conta a estrutura social contemporânea que produz e exalta tais personalidades para fins econômicos. Assim, cumpre ressaltar que as condutas de gestores voltadas para a aplicação de técnicas geradoras de medo e de sentimento de incompetência nos subordinados, por meio de uma participação consciente e deliberada desses atos de injustiça (para a realização de objetivos empresariais) 
Dejours apresenta uma dessas teses encontradas nas práticas discursivas do neoliberalismo que tentam desqualificar a centralidade do trabalho, tanto no plano social quanto no plano psicológico. Uma delas afirma que: "O trabalho não mais suscita problema científico, tornouse inteiramente transparente, inteligível, reproduzível e formalizável, sendo possível substituir progressivamente o homem por autômatos. $\mathrm{O}$

trabalho diz respeito tão somente à execução. Os únicos problemas residuais da empresa residem na concepção e na gestão" (Dejours, 2007, p.42). correspondem ao modelo imperante de homo oeconomicus, que, por sua vez, acaba por apresentar similaridades com o tipo de caráter autoritário exemplificado por Adorno como "consciência coisificada", a saber: pessoas que fazem uso de uma racionalidade prática em prol do discurso da eficiência e do realismo econômico em detrimento de escolhas pautadas na ética e na racionalidade moral (Dejours, 2007). As relações de trabalho calcadas nesse tipo de gestão que desestabiliza formas de solidariedade entre os colegas, que mobiliza nos empregados o sentimento de medo e de angústia, em um clima de constante suspeição e violência, e no qual todo o medo do indivíduo é reprimido e silenciado, só podem resultar em um ambiente mortífero, cujo silêncio é quebrado na morte voluntária de um dos perseguidos, qual seja, o ato suicida do trabalhador no ambiente laboral.

No que diz respeito às fachadas limpas e higiênicas das empresas - as chamadas "vitrines do progresso" -, Dejours diz nelas se esconder uma tendência totalitária e destrutiva. Nas hiper-empresas divulgadas pelo mass media como locais em que se reúnem os homens qualificados, competentes e vencedores, o sofrimento dos que trabalham é evidenciado por detrás dos clichês fabricados pelos discursos correntes, em condições pouco diferentes daquelas de antigamente, e até mesmo piores em termos das infrações de leis trabalhistas (Dejours, 2007). Sob o movimento de intensificação do trabalho produtivo tangenciado por pressões morais exercidas sobre os assalariados, Dejours apresenta, nos casos clínicos estudados, o sofrimento do trabalhador como resultado do medo de não corresponder às imposições do mundo do trabalho, tais como: as imposições de formação técnica e de informação, de rapidez de aquisição de conhecimentos teóricos e práticos e de adaptação à "cultura ou à ideologia da empresa" (Dejours, 2007, p.28). Ao contrário das teses neoliberais vigentes que afirmam não mais ser o campo do trabalho um "problema científico"3 por causa da robotização e da racionalização do trabalho, citamos Adorno (1951/1993) no aforismo "a saúde para a morte". O autor aborda a velha injustiça que ainda continua sob o véu tecnológico e sob a racionalização do trabalho, ou seja, a dor e a violência física ainda subsistem nas relações sociais do capitalismo pós-industrial, bem como as ameaças de exclusão social que, não obstante, impedem a expressão do sofrimento, esse, agora, revertido em conduta de ajustamento. Nas palavras de Adorno:

\begin{abstract}
Assim como a velha injustiça não é alterada pelo emprego maciço e generoso de luz, ar e higiene, mas sim, precisamente encoberta pela cintilante transparência da empresa racionalizada, do mesmo modo a saúde interior de nossa época consiste em ter bloqueado a fuga para a doença sem alterar em um mínimo sequer sua etiologia. As latrinas mal iluminadas foram eliminadas como um incômodo desperdício de espaço e transferidas para o banheiro (1953/1993, p.50)
\end{abstract}

Em outras palavras, o medo do sofrimento corporal, físico e psicológico provocado pelas sofisticadas formas de exploração e de dominação continua vigorando na contemporaneidade, só que, no contexto atual, transformado em motivo de vergonha ou em fraqueza de caráter, visto que a doença social interiorizada pelas pessoas se converteu em formas idiossincráticas de comportamentos considerados normais. As ameaças de violência e de mutilação física e psicológica encontram-se embutidas nas novas formas de gestão, posto que elas também se fundamentam em poderosos aparatos narcísicos de controle a partir dos quais o medo do fracasso, acrescentado ao aumento 
do sentimento de culpa no trabalhador, se tornaram os objetivos primeiros das técnicas de manipulação utilizadas e disseminadas nas empresas. Nas palavras de Adorno: "A ausência de nervosismo e a calma, já transformadas em condição para que os candidatos obtenham as posições mais bem remuneradas, são a imagem do silêncio sufocante que só depois vem a ser infligido politicamente pelos mandantes do chefe de pessoal" (Adorno, 1951/1993, p.50). A energia libidinal que se exige dos sujeitos para a sua adaptação e para a sua vida psíquica saudável - assim como para seus desempenhos no trabalho em vista do ilusório sucesso almejado - é de tal forma extensa que, segundo o autor, efetua-se ao preço da mais "profunda mutilação". Não obstante, a mutilação psíquica acaba por se denunciar nos movimentos e nos gestos padronizados de tais pessoas quando, por um momento, percebemos nelas ações inusitadas de estupidez pática, ou, no caso, as trágicas tentativas de suicídio.

As formas de racionalização do trabalho perpetradas por meios bárbaros e desumanos de gestão cada vez mais se encontram presentes no cotidiano da sociedade, nas relações entre as pessoas e no espaço doméstico privado, sendo que os sujeitos reproduzem no mais íntimo de seus seres os valores e os modos de comportamento que servem para a manutenção do sistema (Marcuse, 1957/1970). Nas sociedades tecnológicas de consumo, presenciamos a desprivatização do tempo livre pela indústria do entretenimento e pela exigência de formação politécnica aos trabalhadores. Em nome do progresso técnico defendido por muitos, testemunhamos um crescente investimento libidinal por grande parte de pessoas para a produtividade do trabalho, tendo em vista que o consumo de objetos e de bens supérfluos de fruição tem aumentado as possibilidades de gozo, assim como também providenciado uma ilusória sensação de liberdade nas pessoas, o que contribui para a perpetuação da lógica dominante de trabalho alienado nas relações estabelecidas. Segundo Marcuse, ao estabelecer as relações da economia política com a psicologia individual “(...) em meio geral de subsistência, a tendência originária das pulsões está quebrada a ponto de não mais ser a satisfação que constitui o conteúdo da vida, mas o trabalho para obtê-la" (Marcuse, 1957/1970, p.62). Dessa forma, ao lado da resignação de muitos às modalidades de trabalho oferecidas, assistimos a uma crescente neutralização de forças de oposição à forma social dominante, o que significa maior subordinação dos sujeitos ao "monstruoso aparelho de produção e distribuição" de forma deliberada, tendo em vista a incorporação psíquica, pelos últimos, das necessidades econômicas criadas pela ordem capitalista mundial. O autor ainda acrescenta que, nessa unidade indivisível do aparelho econômico, político e cultural que converge na formação de subjetividades afeitas a esse estado de coisas - pessoas cujas necessidades são determinadas pelos interesses de grupos dominantes e que, assim, colaboram em reproduzir uma sociedade que tornou a dominação cada vez mais agradável e desejável a todos (Marcuse, 1955/2009) -, presenciamos uma amálgama quase indiferenciável entre trabalho socialmente construtivo e destrutivo. A forma dominante de trabalho nas sociedades de mercadorias e tecnológicas é aquela que se volta, quase que exclusivamente, para a intensificação da exploração da natureza e dos recursos intelectuais e materiais a serviço do capital, ao contrário do conceito de trabalho como condição necessária à humanização do homem, tal como apontado por Marx 
nos Manuscritos Econômicos Filosóficos, relembrados e discutidos por Marcuse (1957/1970). Assim, o autor apresenta as consequências sociais e psicológicas efetivas do modelo imperante de trabalho social totalmente alienado: a liberação de forças destrutivas na sociedade e a retração das pulsões eróticas responsáveis pelo reconhecimento dos sujeitos na cultura e pela possibilidade de fruição e de prazer, que permitem uma vida destituída da presença constante dos sentimentos de medo e de ameaça.

No capitalismo pós-industrial, a dualidade entre Eros e Thânatos postulada pela teoria freudiana tem sido expropriada dos indivíduos e racionalmente administrada pelo saber técnico e científico, ao percebermos que, nas novas organizações, o aumento da agressividade - agora neutralizada pela mentalidade técnico-administrativa - tornouse fator necessário e naturalizado nas relações sociais em proveito de forças mais eficazes, tais como os objetivos da indústria moderna e das grandes corporações (Marcuse, 1957/1970). Desses objetivos, observamos que a tecnologia altamente desenvolvida e os meios de produção têm sido utilizados não só para os benefícios da humanidade - ou seja, não só para tornar a vida humana mais segura e "atenuar a crueldade da natureza" (Marcuse, 1955/2009) - mas também para a produção de bens supérfluos e destrutivos (desde os produtos da indústria cultural até os armamentos e artefatos bélicos), cujos poderes aniquiladores têm seus efeitos mais funestos nos países em desenvolvimento, com a exploração da força de trabalho barata e demais intervenções políticas e econômicas, de natureza belicosa. Não só os mais pobres da Terra que, ao pagarem o preço do progresso, revelam a substância que subjaz às sociedades tecnológicas - a saber, a lógica da máxima exploração para atender aos interesses econômicos de pequenos grupos -, mas também aos homens adaptados, ajustados ao capitalismo. Esses, que atuam em defesa do status quo e defendem a forma dominante de trabalho (pois subordinados à engrenagem produtiva), acabam por se trair ao revelar os vestígios de suas mutilações somáticas e psicológicas, desencadeadas pelo sistema econômico estabelecido, nas suas experiências de vida já atrofiadas. Nessa direção, lembramos que, ao contrário do que Marcuse pressupôs, a automatização e a racionalização do trabalho não liberaram o homem para o "jogo das livres pulsões eróticas", mas sim, acabaram por providenciar novas formas de controle e de domínio sobre o trabalhador, aumentando seu sacrifício e sofrimento psicológico, ocultados, agora, pela falsa liberdade provida pelas sociedades de massa (a liberdade sexual e de consumo). Podemos dizer que a Grande Recusa formulada pelo autor (Marcuse, 1955/2009) - a saber, a revolta orgânica ou a aversão biológica de sujeitos contra as sociedades tecnológicas avançadas que, além da produção do consumo supérfluo também têm aumentado os meios de destruição em graus cada vez maiores -, no contexto das novas organizações de trabalho, transladou-se em energia corporal destrutiva, só que agora retraída para o próprio sujeito, culminando no desejo de morte, e, assim, na sua morte física.

\section{Considerações finais}

O atalho para a morte é contraditoriamente encurtado pelas relações deterioradas estabelecidas no mundo do trabalho, sendo que a morte de um assalariado nesse contexto acaba por revelar o quanto a autoconservação racionalizada e incorporada pelo sujeito tem resultado no seu contrário: a autodestruição. Daí, tendo em vista as discussões acima, com 
relação ao gesto fatal do suicídio no ambiente laboral, perguntamos: o suicídio de sujeitos não se tornou a máxima confirmação de forças históricas que operam no sentido de alimentar a ideologia do sacrifício e o desejo de morte, para que as sociedades tecnológicas e pós-industriais do mundo administrado continuem a funcionar com a sua lógica produtivista altamente destrutiva? Ou seja, mais do que uma mensagem de desespero ou de protesto por parte de quem põe fim à própria vida, assim sinalizando que algo muito cruel subsiste nas relações de trabalho, o ato suicida, em última instância, não seria a confirmação de que o sistema funciona com a sua incontestável prioridade em nome do progresso? O suicídio do trabalhador não seria o reverso da razão autoconservadora? Nesse sentido, a impotência daquele que dá cabo da própria vida no ambiente de trabalho acaba por perpetuar as forças que o mutilaram: o poder das novas organizações de trabalho calcadas na gestão do terror.

Para além das leituras que veem no suicídio uma força de resistência que obriga a buscar a verdade que se esconde por trás das perversas relações de trabalho estabelecidas (Dejours \& Buègue, 2010), eis algumas questões que nos levam a uma triste conclusão: a de que o trabalho morto faz parte do esquema dominante. Mas, segundo Adorno (1951/1993), a "esperança não se encontra nos desesperançados" 


\section{Ana Paula de Ávila Gomide}

Doutora em Psicologia Escolar e do Desenvolvimento Humano pela Universidade de São Paulo e docente da Universidade Federal de Uberlândia, Uberlândia - MG - Brasil.

E-mail: anapaula@fapsi.ufu.br

Endereço para envio de correspondência:

Rua Maria Dória Cunha, 160, Ap. 302, Bairro Jardim Finotti. CEP: 38408-080. Uberlândia, MG.

Recebido 27/04/2011, 1a Reformulação 13/12/2012, Aprovado 22/01/2013.

Adorno, T. W., Frenkel-Brunswick, E., Levinson, D. J., \& Sanford, R. N. (1950). The authoritarian personality. New York: Harper \& Brother.

Adorno, T. W. (1993). Minima moralia. São Paulo: Ática (Trabalho original publicada em 1951).

Adorno, T. W. (1995). Educação após Auschwitz. In T. W. Adorno. Educação e emancipação. (pp.119-139, W. Leo Maar, trad.). Rio de Janeiro: Paz e Terra (Trabalho original publicado em 1969).

Adorno, T. W. (2010). Teoria da semiformação. In B. Pucci \& A. Zuin (Eds.). Teoria crítica e inconformismo: novas perspectivas de pesquisa (pp.7-41). Campinas, SP: Autores Associados (Trabalho original publicado em 1956).

Arendt, H. (1963). Eichmann in Jerusalem. New York, Vilking.

Bauman, Z. (2001). Modernidade líquida. Rio de Janeiro: Jorge Zahar.

Dejours, C. (2007). A banalização da injustiça social. Rio de Janeiro: Editora FGV.

Dejours, C., \& Buègue, F. (2010). Suicídio e trabalho: o que fazer? Brasília, DF: Paralelo 15.

Freud, S. (1974). O mal-estar na civilização. In Obras Completas de Sigmund Freud. (J. Salomão, trad., Vol. 21, pp.75 - 174).
Rio de Janeiro: Imago (Trabalho original publicado em 1930).

Gagnebin, J. M. (1982). Walter Benjamin. São Paulo: Editora Brasiliense.

Heloani, R. (2011). Quando alguém se mata no trabalho, o que está querendo dizer? In M. Barreto \& L. Netto (Orgs.). Do assédio moral à morte de si: significados sociais do suicídio no trabalho. (pp.249-274). São Paulo: Matsunaga.

Horkheimer, M., \& Adorno, T. W. (1985). Dialética do esclarecimento. Rio de Janeiro: Zahar (Trabalho original publicado em 1944).

Marcuse, H. (1970). Teoria das pulsões e liberdade. In H. Marcuse. Progresso social e liberdade (pp. 31-70). Porto: Ed. Textos Marginais (Trabalho original publicado em 1957).

Marcuse, H. (2009). Eros e civilização - uma interpretação filosófica do pensamento de Freud. Rio de Janeiro: Civilização Brasileira (Trabalho original publicado em 1955).

Marcuse, H. (1959). The ideology of death. In H. Feifel (Ed). The meaning of death. New York: McGraw-Hill Book Company.

Santos, M. A. F. (2009). Patologia da solidão: o suicídio de bancários no contexto da nova organização de trabalho. Dissertação de mestrado. Faculdade de Economia, Administração, Contabilidade e Ciências da Informação e Documentação, Universidade de Brasília, Brasília, DF. 